\title{
Lateral Performance for Long Pile Subjected to Simultaneous Axial and Lateral Loads in Dense Sand: An Experimental Study
}

\author{
Jasim M. Abbas*, Qasim I. Hussain \\ Department of Civil Engineering, College of Engineering, University of Diyala, Iraq \\ *corresponding author email: jasimalshamary@yahoo.com \\ qasim.ibrahim2015@gmail.com
}

\begin{abstract}
The present study focus on the investigation ofthe response of single pile when subjected to both axial and lateral loads simultaneously in dense sand. To study this issue, laboratory model was locally improved to examine the piles under this kind of loading. The dense sand provided using raining technique. The slenderness ratio of the tested pile is $(\mathrm{L} / \mathrm{D}=45)$. On the other hand, the vertical and horizontal loads are divided into 5 stages to assess the influence of load intensities on the lateral pile response. It can be concluded that the lateral pile response is affected by changing the load intensities
\end{abstract}

Keywords: Piles; Lateral response; Sand.

Paper History: Received: 25/1/2018; Accepted:

27/3/2018

\section{Introduction}

In fact, piles foundationare structural member which made from timber, steel, or concrete, used to support the structures and to transfer the loadsto the deep layers of soil that have adequate bearing capacity to support the structures. Always piles were subjected to vertical loadswhich result from the weight of the structures and to lateral loads result from wave, wind or earth quake especially when the piles used in the offshore structures. Actuality, piles are subjected to both vertical and lateral loads in the same time, so it is important to know the response and the behavior of piles in such cases especially when the studies are limited in such way.

A number of pervious study takes into account the effect of pure lateral load on piles, these studies were early reported by (Broms 1964, Reese et al. 1974), and continuously improved until present (Awad 1999; Prasad and Chari 1999;Janoyan et al. 2001;Bouafia 2007; Abbas et al. 2008 and 2014; Ozden and Akdag 2009; Rahman et al. 2009; Fatahi et al. 2014; Abdrabbo andEl Wakil 2016, and others). While, there are little works take into account the effect of both axial and lateral load on piles (Banerjee 1978; Karthigeyan et al. 2006 and 2007; Lee et al. 2011; Khodair and Abdel-Mohti 2014, Park et al. 2016).

Based on the menstioned study it can be shown that the study about the pile behavior under combined loads is limited, therefore this study included experimental tests for lateral pile performance with the effect of the presence of the vertical load in the same time in dense sand.

\section{Materials Used}

\subsection{Sand}

The sand used in the present study was brought from Karbalaa governorate, Iraq. The laboratory tests were conducted on it to explain its physical properties according to the ASTM specification. Figure (1) and Table (1), explain the physical properties of the sand used.

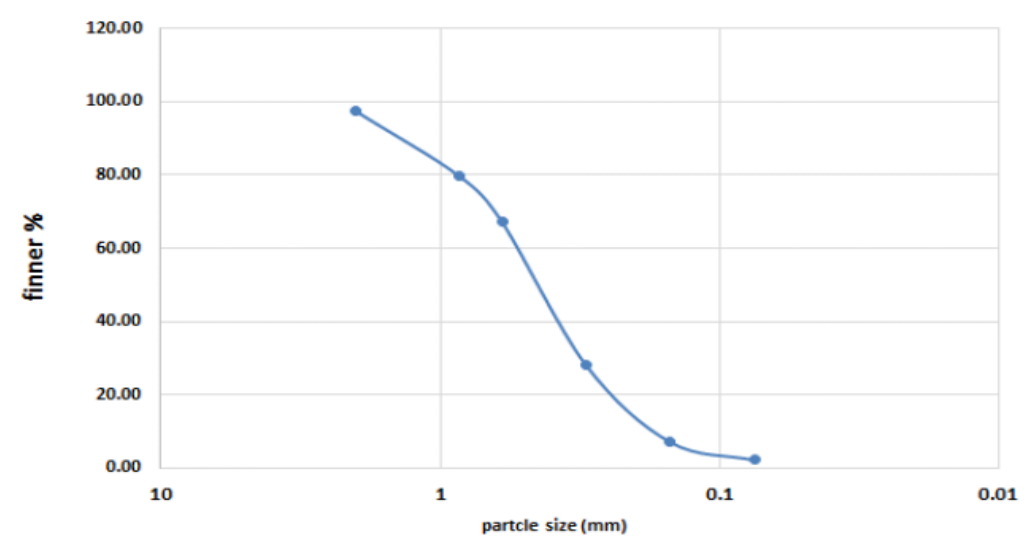

Figure 1:Particle size distribution of the used sand 
Table 1, The physical properties of the used sand

\begin{tabular}{|c|c|}
\hline Physical properties & Amount \\
\hline $\mathrm{D}_{50}$ & 0.45 \\
\hline $\mathrm{D}_{10}$ & 0.191 \\
\hline $\mathrm{D}_{30}$ & 0.32 \\
\hline $\mathrm{D}_{60}$ & 0.55 \\
\hline Coefficient of uniformity, $C_{u}$ & 2.88 \\
\hline Coefficient of curvature, $C_{C}$ & 0.98 \\
\hline Classification based on USCS & $\mathrm{SP}$ \\
\hline Specific gravity, $G_{S}$ & 2.67 \\
\hline Dry unit weight, $\gamma_{d}\left(\mathrm{kN} / \mathrm{m}^{3}\right)$ & 14.703 \\
\hline Angle of internal friction, $\varnothing$ & 36.8 \\
\hline
\end{tabular}

\subsection{Pile}

The pile used in the present study was made of steel material with diameter (D) of $1.5 \mathrm{~cm}$, wall thickness $(\mathrm{t})$ $0.1 \mathrm{~cm}$, and slenderness ratio (L/D) of 45 .

\subsection{Model Tank}

The model tank that used in the present study was locally manufactured with dimensions of $(100 \mathrm{~cm} x 100 \mathrm{~cm}$ $\mathrm{x} 100 \mathrm{~cm}$ ) to prevent any interface between the effective zones of the piles used, and also to prevent the frictionbetween the container wall and the soil used which may affect the obtained test results.

The laboratory model was made from steel plate of thickness equal to $4 \mathrm{~mm}$. All the sides of themodel tank were fixed together via a number of screws as shown in the figure below.Figure 2 show the laboratory testing model that included all equipment's and the location for each

part.

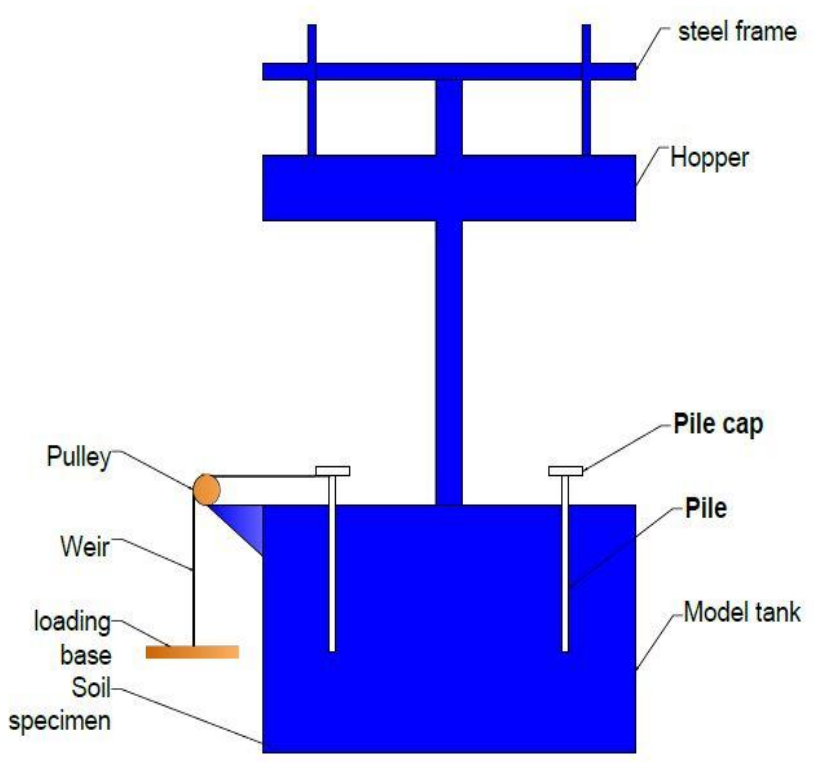

Figure 2: The laboratory model

\section{Experimental Work}

In the current study the pile used were subjected to both vertical and lateral loads. At initial stage the strain gauges were fixed at the pile side figure (3) to measure the lateral deflection of pile inside the soil. After that the pile model was placed in the laboratory model in the required depth by using steel mesh which fixed above the sides of model tank, the soil used (sand) was placed in the same tank from a required height $(0.6 \mathrm{~m})$ for obtaining the required placement density in the test via using the raining technique. The lateral load was applying on the pile by using a wire which attached by the cap of the pile from one direction and from the other it is related to the loading base via frictionless pulley. The lateral deflection of pile above the soil surface was measured by two dial gauges above the soil surface fixed at the pile cap and the lateral 


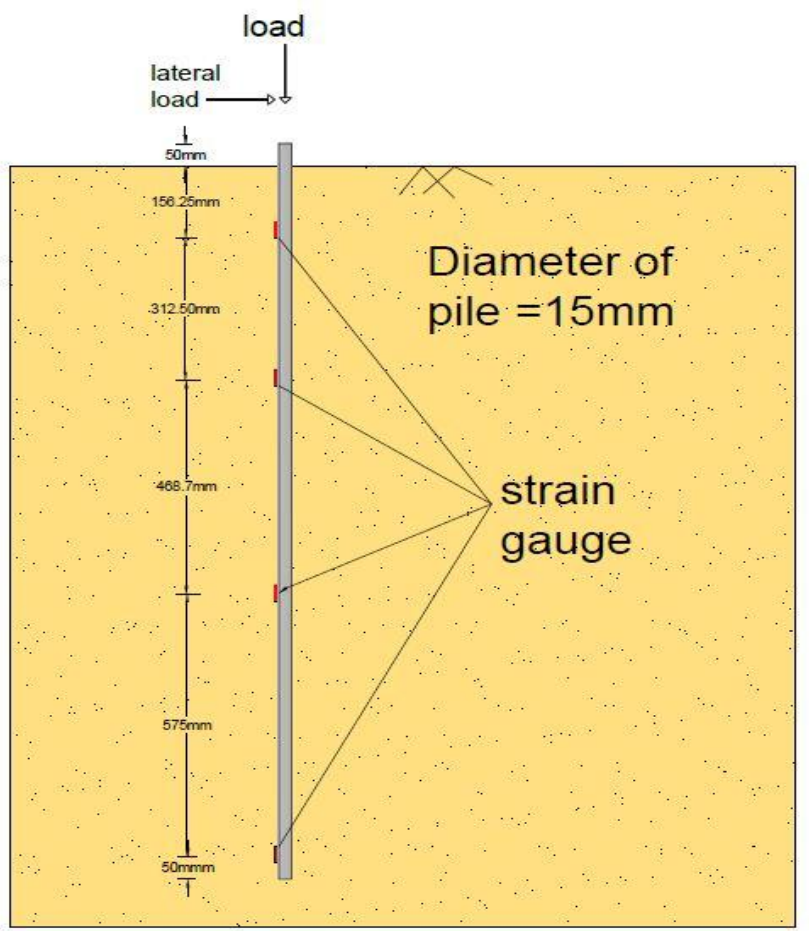

Figure 3: The location of the strain gauges at the pile side

The amount of lateral load that used in the current study is equal to $20 \%$ of the allowable vertical load of the pile used and applies infive increments on pile. In each increment the lateral displacement was measured by using two dial gauges (sensitivity of $0.01 \mathrm{~mm}$ ) which fixed on the pile cap and by strain gauges fixed along the pile. Vertical load is apply on the pile with the appliedof lateralload in five stages $(0 \%, 20 \%, 40 \%, 60 \%, 80 \%$, $100 \%$ from the allowable vertical load).

\section{Test Results and Discussion}

The load- displacement curves were plotted for the pile used as shown in figure 4to explain the effect of the presence of the vertical load on the lateral response of
pile.The lateral deflection of pile was measured by using dial gauge which is fixed on the pile head and for the embedded length of pile, the lateral deflection was measured by using strain gauges fixed at the pile side in the direction of load. From figure 4 it can be shown that when the vertical load is between $20 \%$ and $60 \%$ from the allowable vertical load, the lateral capacity of pile increases about $15.8 \%$ and $1.2 \%$ respectively, this is possibly due to the increase of pile stiffness due to increase of axial load. While, when the applied the vertical load more than $80 \%$ from the allowable vertical load, the lateral capacity of pile decreases to reach about $33.8 \%$. This is possibly due to increases the effect of p-delta phenomena. 


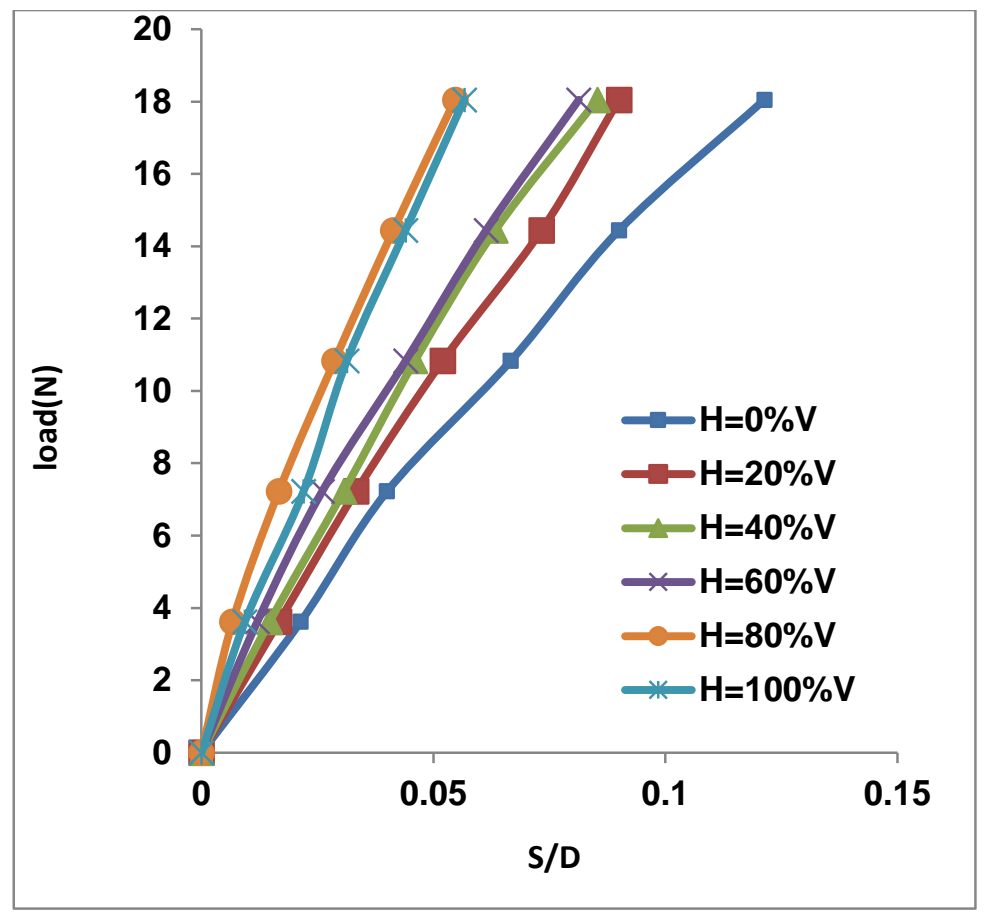

Figure 4:The load- displacement relationship for pile tip

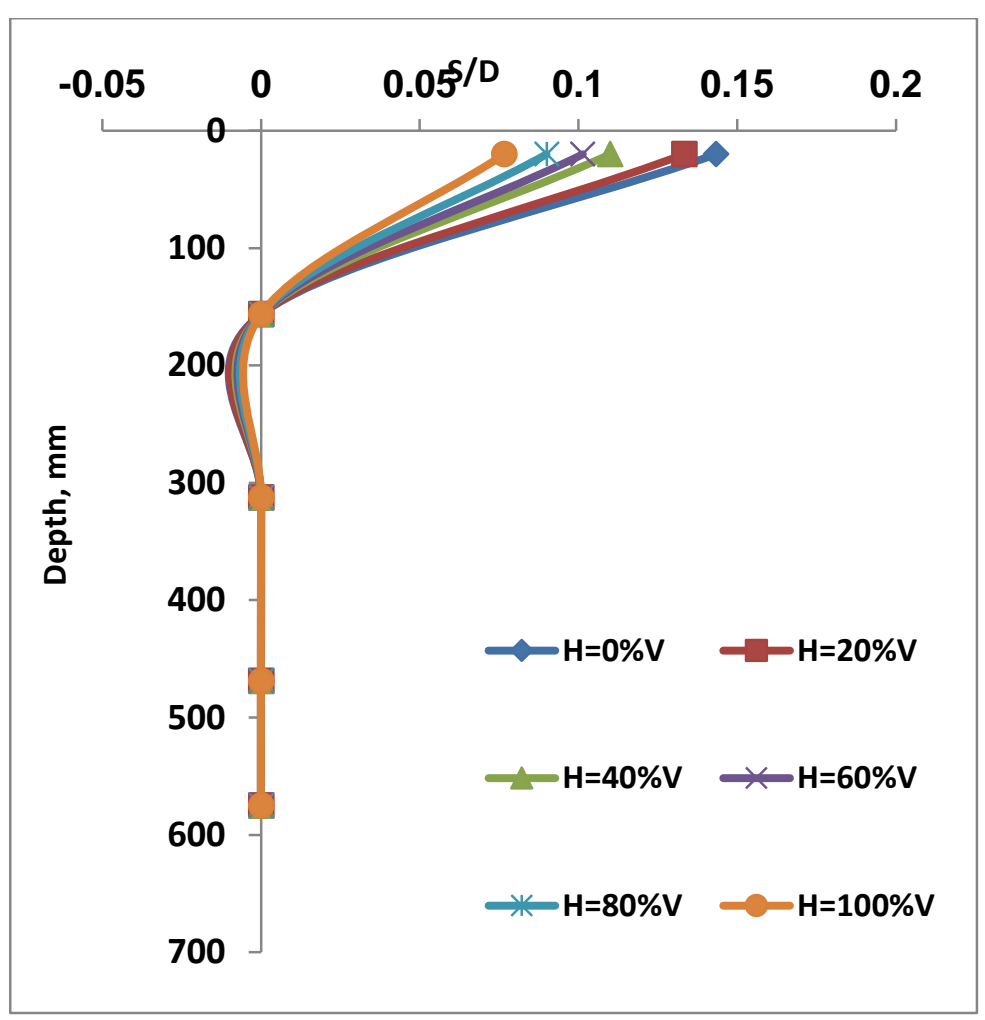

Figure 5: The lateral pile deformation with depth

Figure 5 explains the lateral pile deformation with depth that is obtained by strain gauges which are fixed at the pile side.From that curves it can be shown that the position of the flexural point is $156.25 \mathrm{~mm}$ from the soil surface, flexural point is the point where the shear force is zero and the bending moment is in the maximum
value.Thuse,the amount of load increases reduces the deformation value of the substrate

\section{Conclusions}

Based on the test result it can be show that the presence of the vertical load affect the lateral response of pile and the large effect of vertical load can be seen when 
its amount it is 20 and $60 \%$ from the allowable vertical load of pile.

From the test results it can be shown that when the vertical loads applied on the pile is $20 \%$ and $60 \%$ from the allowable load then the lateral capacity of pile increases about $15.8 \%$ and $1.2 \%$ respectively and when the vertical load applied on the pile are $40 \%, 80 \%$, and $100 \%$, then the lateral capacity of pile decreases. The location of the flexural point is $156.25 \mathrm{~mm}$ from the soil surface.

\section{Acknowledgment}

This work was supported by University of Daiyla, Civil Engineering Department, which is gratefully acknowledged.

\section{References:}

[1] Abdrabbo, F. M., and A. Z. El Wakil. "Laterally loaded helical piles in sand." Alexandria Engineering Journal 55.4 (2016): 3239-3245.

[2] Awad, DR Mohammed. "Lateral load tests on minipiles." Islamic University Journal 7.1 (1999): 15-33.

[3] Abbas, J M, Mohammed Shafique Q S. and Taha M R. 2008.Effect of shape and slenderness ratio on the behavior of laterally loaded piles. The 1st Regional conference of Eng. Sci. NUCEJ Spatial ISSUE $.11(1), 19-27$.

[4] Abbas, J M, 2014. Bridge Pile Foundation: Simulation and Analysis. Journal of Earth Sciences and Geotechnical Engineering 4 (1), 131-143

[5] Abbas J M., Chik Z, Taha M R, 2008, Single pile simulation and analysis subjected to lateral load. EJGE,vol.13, Bund. E, 1-15.

[6] Banerjee, P. K., and T. G. Davies. "The behaviour of axially and laterally loaded single piles embedded in nonhomogeneous soils." Geotechnique 28.3 (1978): 309-326.

[7] Bouafia A. 2007. Single piles under horizontal loads in sand: determination of P-Y curves from the preboredpressuremeter test. GeotechGeolEng, 25: 283301.

[8] Broms, Bengt B., (1964), Lateral resistance of piles in cohesionless soils. JSMFD, ASCE, 90, SM3, 123-156.

[9] Fatahi, Behzad, et al. "Performance of laterally loaded piles considering soil and interface parameters." Geomechanics and Engineering 7.5 (2014): 495-524.

[10] Janoyan, K., Jonathan P. Stewart, and John W. Wallace. "Analysis of py curves from lateral load test of large diameter drilled shaft in stiff clay."
Proceedings of the 6th Caltrans workshop on seismic research, Sacramento, CA. 2001.

[11] Karthigeyan, S., Ramakrishna, V. V. G. S. T., and Rajagopal K. (2006). "Influence of vertical load on the lateral response of piles in sand." Computer and Geotechnics, 33, pp121-131.

[12] Karthigeyan, S., Ramakrishna, V. V. G. S. T., and Rajagopal K. (2007). "Numerical Investigation of the Effect of Vertical Load on the Lateral Response of Piles." Journal of Geotechnical and Geoenvironmental Engineering, 133(5), 512-521.

[13] Khodair, Yasser, and Ahmed Abdel-Mohti. "Numerical Analysis of Pile-Soil Interaction under Axial and Lateral Loads." International Journal of Concrete Structures and Materials 8.3 (2014): 239-249.

[14] Lee, J., Prezzi, M. and Salgado, R. (2011), Experimental investigation of the combined load response of model piles driven in sand. Geotechnical Testing Journal, 34(6), 653-667. .

[15] Ozden, Gurkan, and Cihan Taylan Akdag. "Lateral load response of steel fiber reinforced concrete model piles in cohesionless soil."Construction and Building Materials 23.2 (2009): 785-794.

[16] Park, J. H., Y. Shin, and M. Chung. "Experimental study on axial and lateral bearing capacities of nonwelded composite piles based on pile load test results."2016.

[17] Prasad, Yenumula VSN, and T. R. Chari. "Lateral capacity of model rigid piles in cohesionless soils." Soils and Foundations 39.2 (1999): 21-29.

[18] Rahman, M. M., Karim, M. R., Baki, A. L. and Paul, D. K., (2009), Ultimate Lateral Load Resistance of Laterally Loaded Pile. University of Canterbury. Civil and Natural Resources Engineering.

[19] Reese, L. C., Cox, W. R. and Koop, F. D. (1974), Analysis of Laterally Loaded Piles in Sand. Proc. 6th Offshore Tech. Conf. Houston, Texas. 